\title{
Project Governance: Balancing Control and Trust in Dealing with Risk
}

Zwikael, O., Smyrk, J. (2015). Project governance: Balancing control and trust in dealing with risk. International Journal of Project Management, 33 (4), 852-862.

\begin{abstract}
Organizational performance can be enhanced by effective project benefit generation. Although it identifies the project owner as the single point of accountability for the realization of project benefits, the literature does not comprehensively discuss this role in the project governance model, nor the management approaches that can support this role. Based on principal-agent theory and a control-trust-risk approach, we have conducted an empirical study across various managerial contexts. Results suggest that trust of the project owner in the project manager is more effective in a turbulent environment, whereas more control by the project owner of the project management process is a superior management approach in a more stable project setting. Finally, a project governance model is introduced and the management role of the project owner is discussed.
\end{abstract}




\section{Introduction}

Successful projects enhance productivity and organizational value (Lee et al. 2011; Shenhar \& Dvir 2007). One of the major determinants of their success is an effective project governance structure (Lechler \& Dvir 2010). Project governance seeks to create the conditions for ordered rule and collective action (Stoker 1998) by providing a formal representation of the organizational arrangements that surround a particular project. Given the temporary nature of projects (Malach-Pines et al. 2009; Bakker et al. 2013), each one requires a unique governance structure which, while distinct from the relatively stable standing structures of the participating organizations, must nevertheless, co-exist with them. The assignment of accountabilities to certain entities in the project governance model is important (Too and Weaver 2013), because it helps bridge the gap between the expectations of a role and the way that role is filled (Forbes \& Milliken 1999) by attaching sanctions and rewards to levels of performance (Zwikael \& Smyrk 2011). Existing literature accepts project managers as accountable for delivering outputs efficiently - to specification, on time and within budget (Lewis et al. 2002). Such a view is consistent with the assumption that projects are undertaken to deliver outputs (deliverables which take the form of artifacts, such as a bridge, or an information system).

However, literature also challenges existing project governance models, suggesting they are dated, incomplete, and of questionable value (Lechler \& Cohen 2009; Zwikael \& Smyrk 2012). In particular, a major criticism is that such models are not reflective of recent developments in the project management literature, especially those that view projects as exercises aimed at realizing benefits desired by the funding organization (Scott-Young \& Samson 2009). 'Benefits', defined as 'flows of value that arise from a project' (Zwikael \& Smyrk 2012), for example 'increased market share' or 'reduced operating costs'. While the 
importance of project benefits is well accepted (Shenhar \& Dvir 2007), accountability for their realization appears to be treated ambiguously in the literature (Remenyi et al. 1997). As a result, this paper aims at understanding the impact of management accountability approaches for benefit realization on project performance and their implications for project governance. The research questions this paper attempts to answer are: (1) 'does assignment of benefit realization accountability improve project performance?', (2) 'to whom might such an accountability be assigned?', and (3) 'what are the most effective management approaches to support this role?'. The paper includes the development of a theoretical framework, discussion of a quantitative study aimed at its validation, and introduction of a generic project governance model.

\section{Related theories and hypotheses development}

This section reviews the governance literature and principal-agent theory as a foundation on which to discuss the assignment of an accountability for benefit realization. It then applies the control-trust-risk approach to establish appropriate management approaches for this role, and develops a series of research hypotheses.

\subsection{Project governance}

Recent international financial scandals and the collapse of high profile corporations, such as Enron and World-Com have brought into prominence the role of governanceparticularly as it relates to corporate performance (Bozec et al. 2010). Nigro et al. (2012) stressed the importance of designing governance models to deal with the issues of inter-firm relationships, following concepts of Transaction Cost Economics. In general, governance provides a framework for ethical decision making and managerial action within an organization that is based on transparency, accountability, and defined roles. Corporate 
governance concerns the manner in which corporations are regulated and managed $(\mathrm{du}$ Plessis et al. 2005), and deals with the need to balance achievement of the organization's goals with those of its stakeholders, including society in general and shareholders in particular. A governance structure seeks to reduce conflicts amongst different groups of stakeholders that might otherwise impact negatively on performance, and provides a framework through which the objectives of the organization are set (OECD, 2004).

For similar reasons, projects-unique processes (Marle et al. 2013) intended to realize target benefits (Zwikael \& Smyrk 2012)—also require their own governance models. Whereas organizational structures are typically functionally-oriented, members of the teams involved in projects are usually drawn from across functional and organizational boundaries (Sundstrom et al. 1990), and so standing organizational governance structures are rarely suited to projects - each of which requires a separate arrangement.

The literature has no commonly understood and agreed upon definition for project governance (Bekker, 2014). Renz (2008, p. 356) defines project governance as "a processoriented system by which projects are strategically directed, integratively managed, and holistically controlled, in an entrepreneurial and ethically reflected way". The Project Management Body of Knowledge $\left(\mathrm{PMBOK}^{\circledR}\right)$ defines project governance as "the alignment of project objectives with the strategy of the larger organization" (PMI, 2013, p.553).

Moreover, the literature does not agree on the structure of a robust project governance model (Zwikael and Smyrk, 2011), only that it should be based around four key principles (Garland 2009): (1) identify a single point of accountability, (2) ensure a service delivery focus, (3) separate the project and the organization governance structures, and (4) separate stakeholder management and project decision making. Similarly, Turner (2009) suggested three steps for project governance: (1) define the objectives, (2) define the means to achieve the objectives, and (3) define the means of monitoring the progress. PRINCE2 (OGC, 2009, 
p. 306) argues project governance should “ensure that an organization's project portfolio is aligned to the organization's objectives, is delivered efficiently; and is sustainable." Muller (2009) suggests governance models should help fostering projects to be successful, prioritize projects for best use of resources, identify projects in trouble, and rescue, suspension, or termination of these projects as appropriate.

Consequently, literature also suggests various project governance models. Ruuska, Ahola, Artto, Locatelli and Mancini (2011: 650) identified three main categories of project governance models based on the variety and level of stakeholder involvement: a single firm's governance scheme with its multiple projects, multi-firm projects where various companies engage in contractual agreements, and projects as hybrid or network like structures involving multiple interconnected actors relying on the presence of one supreme hierarchical authority. Morris and Geraldi (2011: 20-23) argued that the management of projects could be viewed at three functional levels: technical, strategic, and institutional. Bekker (2014) combined the two models described above into three 'schools of thoughts' - single firm, multi-firm, and large capital. Finally, based on transaction cost economics, Winch (2001) proposed to extend the narrow focus on transactions with the project client.

However, project governance models have lagged behind developments in the project management literature. Recent literature accepts that projects have specific benefits to achieve (Shenhar \& Dvir 2007) and that the delivery of outputs is a (necessary but insufficient) precondition to the realization of those benefits (Zwikael and Smyrk, 2012). Despite this fundamental shift in the focus of the literature, little has been revealed about the implications of benefit realization for project governance (Remenyi et al. 1997). In particular, while the literature tends to be very prescriptive about outputs-related roles in projects (Pryke 2005), discussion about project benefits ignores the concept of accountability for their realization (Muller \& Turner 2005). Even where the emergence of new roles related to 
benefit management has been recognized (e.g. OGC 2009), the need to formalize them with supporting accountabilities has been disregarded. Hence, this paper seeks to determine not only whether models of project governance should be augmented with a supporting accountability for benefit realization, but also how such a role could be reconciled with the project manager's accountability for output delivery (Herroelen 2005; Dvir \& Lechler 2004). The next section discusses principal-agent theory as a foundation for this core accountability.

\subsection{Principal-agent theory}

The project governance model is influenced by various organizational theories (Renz, 2008). Stakeholder theory (Freeman 1984) emphasizes the identification of key stakeholders, such as customers and beneficiaries. Stewardship theory (Davis et al. 1997) emphasizes the role of projects to guide stewards in the deployment of the resources that others have entrusted them. In institutional theory (Aoki 2001), governance has a role in identifying societal expectations of an organization and in confirming that a project is coherent with its

goals. Finally, resource dependency theory (Pfeffer and Salancik, 1978) suggests that projects are shaped, not only by the funding organization, but also by those who have been commissioned (as agents) to provide necessary resources.

This paper analyzes project governance through the lens of principal-agent theory (Eisenhardt 1989) as the most widely recognized approach in the project governance literature (e.g. Turner, 2009). The theory claims that it is inefficient for principals to assume direct responsibility for the management of the organization (Fama \& Jensen 1983) and highlights the resulting goal conflict that arises when individuals with differing preferences engage in cooperative effort. As a result, the application of principal-agent theory results in the separation of ownership from control (Bozec et al. 2010), because the principal engages an agent to perform some service on his/her behalf. Such an arrangement usually involves 
delegation to the agent of certain accountabilities_- together with supporting decision making authority. Principal-agent theory is preoccupied with determining the optimal form of contract (expressed in terms of desired behaviors and outcomes) in the principal-agent relationships (Eisenhardt, 1989). This stream has a broader focus and is applied to employeremployee, lawyer-client, and buyer-supplier relationships. Because of the generality of its context, principal-agent theory has also been usefully extended to the project environment (Muller \& Turner 2005).

A core element of principal-agent theory is the concept of accountability (Jensen 2000). Accountability is also a critical characteristic of effective governance (Brand 2007; Roberts et al., 2005; Huse, 2005; Abednego \& Ogunlana, 2006). Because accountability is particularly important in the project context (Abednego \& Ogunlana 2006; Lechler \& Cohen 2009), and following criticism surrounding its application to project benefits (Remenyi et al. 1997; Zwikael \& Smyrk 2011), this paper focuses on accountability for project benefit realization.

\subsection{Project benefit accountability}

The principal in a project setting is also known as the "funder" (Zwikael \& Smyrk 2012). The funder (commonly the owner of the firm or a senior executive) is the person with the authority to approve the project and commit resources for its execution. In the conventional outputs-based view of a project (e.g. Jensen 2000), the application of principalagent theory (Eisenhardt 1989) gives rise to an arrangement in which the funder (as principal) assigns accountability for efficient output delivery to a project manager (as agent). When the accountability for realization of benefits is introduced, however, a project governance issues is raised: "who should be assigned such an accountability?". There are two immediate options for the assignment of project benefit accountability: the funder can decide to be self- 
accountable or assign such that accountability to the project manager as an agent. This section will show why neither of these is desirable.

Because of their seniority and the associated demands on their time, project funders are often unable to involve themselves meaningfully in particular projects. Consistent with principal-agent theory, funders may elect to delegate accountability for benefit realization to someone else in their organization-to whom is also delegated various authorities (especially related to funding). Because the establishment of such agency arrangements shifts project decision-making out to others (away from the funder), delegation of this kind forces a degree of decentralization on the funding organization. The advantages of decentralization (through the delegation of decision-making) are well documented in the literature. For example, Mihm et al. (2010, p. 831) suggest that decentralization "increases solution quality, and raises the organization's ability to cope with environmental changes". Aghion \& Tirole (1997, p. 27) argue that such delegation "will both facilitate the agent's participation in the organization and foster his incentive to acquire relevant information about the corresponding activities". Delegation is especially relevant when a "principal is overloaded with too many activities... and therefore has little time to acquire the relevant information on each activity". In such a situation the principal loses "effective control and involuntarily endorses many suboptimal projects" (Aghion \& Tirole 1997, p. 3). Under the model proposed by Aghion \& Tirole (1997, p. 5) "the principal hires the agent to collect information about and implement the project".

While the principal needs to appoint someone to be held accountable for benefit realization, we draw on existing theories to argue that such a role should not be filled by the project manager. Firstly, because conflicts of interest must be avoided (Simon 1976), future benefit realization cannot be compromised in the immediate interests of efficient output delivery (for example, by making a conscious trade-off between the eventual magnitude of a 
benefit and completing the project on time). Secondly, we invoke the principle that in a transaction, a "purchaser" is to be identified and separated from the role of "provider" (Muller \& Turner 2005). A project can be viewed as a transaction in which a client (the funder) orders a product (output) from a supplier (the project manager) for an agreed fee (the budget). Thirdly, project managers usually have a mindset that better suits output delivery, rather than the realization of organizational benefits (Kerzner 2009). Lastly, the role of project manager is, in any event, a transient position — to which the attachment of long-term accountabilities may be most inappropriate (Zwikael \& Smyrk 2012). Taken together, these principles offer further support for the claim that "benefits are not delivered or realized by the project manager and project team" (Cooke-Davies 2002). If neither the funder nor the project manager is to be held accountable for benefit realization, a different entity is required to fill that role.

This paper suggests that a "Project Owner" acts (as agent) on behalf of the funder (as principal), seeking to ensure that the interests of the latter are being served throughout a project. Similarly, the UK government (OGC, 2009) has defined a "Senior Responsible Owner" as "a single individual with overall responsibility for ensuring that a project or program meets its objectives and delivers the projected benefits". The project owner should be a senior executive who might be responsible after project completion for any ongoing operation of its outputs. Because, in such cases, benefit accountability is associated with a business unit, it would be usefully delegated to front-line management (Mihm et al. 2010), and so a functional manager is often a good candidate to fill this role. For example, if a project is to deliver a new incentive scheme so that staff turnover can be reduced, it would be appropriate to appoint the Head of HR as the project owner-who then becomes accountable to the $\mathrm{CEO}$ (as the funder) for the achievement of reduced staff turnover through the project. Roberts et al. (2005) introduced the concept of "effective accountability" claiming it to be 
highly important in corporate governance. Similarly, we argue here that effective accountability for benefit realization is important in the project governance context. Hence, we hypothesize that:

\section{$H_{1 a}:$ Effective accountability for benefit realization enhances project performance}

Whereas the first hypothesis suggests a direct effect on 'project performance', recent literature has criticized the use of a single, overarching measure (e.g., Scott-Young \& Samson 2008; Muller et al. 2012), as it does not allow factors that contribute to separate dimensions to be distinguished (Pinto \& Prescott 1990). An alternative approach distinguishes separate dimensions of performance (Jugdev \& Muller 2005; Pinto \& Prescott 1990). One of these dimensions commonly used in research (e.g. Aviram-Unger et al., 2013) is "efficiency", refers to meeting the agreed time and budget targets. Scholars (e.g., Dvir \& Lechler 2004; Narayanan et al. 2011) have argued that the relationship between project management factors and performance is mediated by project efficiency. That is, a project meeting its efficiency targets is more likely to show improved performance than one which does not meet those targets. Hence, we propose a competing hypothesis:

\section{$H_{1 b}:$ Efficiency mediates the relationship between accountability for benefit realization and project performance}

\subsection{Management approaches to the discharge of accountability for project benefits}

In order to support the project owner role, a model of managerial intervention is required. Todeva and Knoke (2005) provide us with two separate approaches for managerial intervention: (1) Control, a formal mechanism which is associated with legal documents, such as a contract, enables the control of processes surrounding resource allocation and 
decision making; (2) Trust, the confidence in another's will, or faith in a partner's moral integrity. Trust is associated with mutual understanding, unrestricted learning, and interorganizational knowledge-sharing and can substitute a more formal control mechanism by avoiding several types of transaction costs, while still ensuring the other party meets their obligation.

Similarly, in the project context, the project owner who holds the accountability for benefit realization (as an agent of the funder) can frame the relationship with the project manager based on these two approaches. One option involves a high level of control by the project owner of the project manager's activities, for example, by extended reporting requirements, and frequent progress presentations to the project steering committee. The alternative approach reflects a higher degree of trust by the project owner in the project manager by permitting him/her to make operational decisions 'on the run', thus allowing the project to progress more smoothly (with fewer interruptions). The next section discusses the contingent effectiveness of these two management approaches (control and trust) under various levels of project risk.

\subsection{The moderating effect of risk on the effectiveness of different approaches to benefit}

\section{accountability}

Risk is associated with an uncertain event (Wang \& Yang 2012) that, if it occurs, can have a negative effect on achieving project objectives (Zwikael \& Smyrk 2011). Although risk cannot be fully eliminated, Chapman \& Ward (2004) found that organizations spend significant funds in risk management. Research into projects (Zwikael \& Ahn 2011; Lewis et al. 2002) and governance (Cui et al. 2012) suggests that risk is an important moderator for performance. 
In particular, risk has also been found an important moderator in the selection of an appropriate accountability management approach. Das and Teng (2001) discussed two types of risks: (1) relational risk is the perceived threat that a firm will behave opportunistically and consciously harm its partner's interests, and (2) performance risk is the perceived chance that factors such as market uncertainty, competition and governmental regulation may have negative effects on results. In the context of project governance, because of the immediate impact on project results, performance risk is the most relevant dimension (Zwikael \& Smyrk 2012). The control-trust-risk approach suggests that performance risk moderates the impact of control and trust approaches on performance, such that control is the preferred option "in a stable environment with low performance risk, whereas trust is required in a turbulent environment with high performance risk" (de Man and Roijakkers, 2009, p. 78). Hence, in the project environment we expect control approaches to have stronger impact on on project performance under low levels of project risk, whereas trust to have stronger impact in high risk scenarios. Hence, the following moderation hypotheses are proposed (also illustrated graphically in Figure 1):

\section{$H_{2 a}:$ Risk moderates the relationship between control and performance, such that the} impact of control on project performance is stronger in low risk projects than in high risk projects

\section{$H_{2 b}:$ Risk moderates the relationship between the trust and performance, such that the} impact of trust on project performance is stronger in high risk projects than in low risk projects

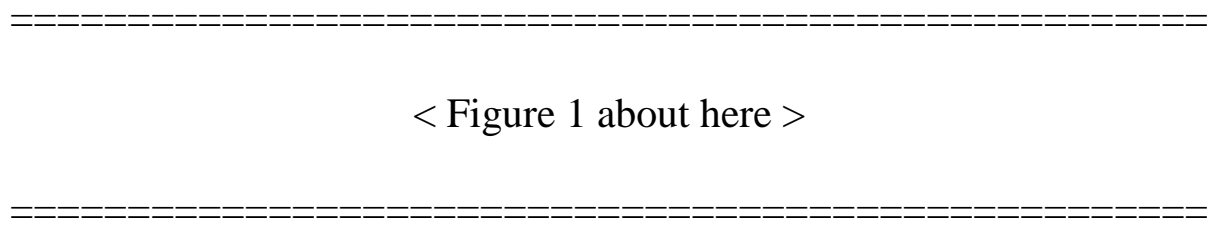




\section{Research design}

In order to test these hypotheses, an approach based on quantitative study using a survey was chosen, as it can test constructed theories, and produce precise and numerical data (Johnson \& Onwuegbuzie, 2004). This section summarizes the method and measures used.

\subsection{Participants and procedure}

The unit of analysis in this study was a project. For each project, two questionnaires were used - the first targeted project managers who were asked to report on trust, control and risk in the most recent project they had managed, as well as to provide contact details of their supervisors. A call for participation in the study was sent in an email to members of the Project Management Institute in the Asia Pacific region. This group was chosen because of their familiarity and experience with the project environment. Following completion of the first questionnaire, a second questionnaire, which was matched to the first one using a project code, was administrated to the supervisors. Referring to the same project, project managers' supervisors were asked to assess the level of project performance. This approach has enabled us to minimize same source bias.

Out of the 102 complete project manager-supervisor dyads received, 29 responses came from India, 16 from New Zealand, 15 from Australia, and the rest from different Asia Pacific countries. $20.2 \%$ of responses came from software organizations, $19.0 \%$ from services, $11.9 \%$ from engineering, $13.1 \%$ from government, and $8.3 \%$ from production organizations. Project duration ranged between 2 and 60 months with a mean of 15.6. 55.4\% of the projects were undertaken for an internal funder within the same organization, while $44.6 \%$ of the projects were commissioned by an external organization. $89 \%$ of responses were male and $11 \%$ female. 


\subsection{Measures}

Project performance. Based on Aviram-Unger et al. (2013) this construct was measured using two items that represented the project funder's level of satisfaction with the realized benefits at project completion. The two items were: "funder's satisfaction with the project at its end" and "extent to which the project deliverables were fit-for-purpose". The items were measured on a five-point Likert scale $(1=l o w$ to $5=h i g h)$. The scale's alpha coefficient was .84 .

Project efficiency. 'Project efficiency' was measured by two items: time and cost overruns, as suggested by Bryde (2005). Participants were asked to indicate the extent to which the project deviated from planned schedule and cost (in percentages), as set at the start of the project. 'Project efficiency' was then calculated as the reversed average of the two reported variables to ensure higher scale values represent higher levels of efficiency. The scale's alpha coefficient was .69.

Project benefit accountability. This independent variable was measured using a two item scale with reference to both trust and control approaches described earlier (Todeva and Knoke, 2005). 'Trust' was represented by the project owner's 'level of acceptance' (as principal) of delegating management responsibilities to the project manager (Abednego \& Ogunlana 2006). 'Control' was assessed by the 'level of project involvement of the project owner in the project management process' (Pfeffer \& Salancik 1978). These variables were gauged using a five point Likert scale (1=low to $5=h i g h)$. The scale's alpha coefficient was .78 .

Project risk. Based on Zwikael and Ahn (2011), the level of this variable was reported by project managers. They were asked to estimate the level of project risk at the commencement of each project on a five point Likert scale (1=low to $5=h i g h)$. 


\subsection{Data analysis}

In this study we used two data analysis approaches to test our hypotheses. The first set of hypotheses was tested by Structural Equation Modeling (SEM), as it involved direct impact and mediating paths. We compared the fit of nested alternative models based on model parsimony and overall Chi-Square. A model that is more parsimonious and has significantly smaller Chi-Square value will be considered as a better fitting model. Because the evaluation of SEM requires multiple measures (Dvir \& Lechler 2004) two were used. The Root Mean Square Error of Approximation (RMSEA) is a measurement of non-centrality, which estimates how well the fitted model approximates the population covariance matrix per degree of freedom. Browne \& Cudeck (1993) suggested that an RMSEA value smaller than 0.08 indicates a close fit and that the model should be accepted. The Comparative Fit Index (CFI) assesses the relative reduction in lack of fit, with a threshold value of 0.85 (Bentler \& Bonett 1980). Further, we used Akaike's (1987) information criterion (AIC) to evaluate the relative fit of our best-fitting model and a non-nested alternative model, where smaller AIC values represent better fit.

Moderating hypotheses $\left(\mathrm{H}_{2 \mathrm{a}}\right.$ and $\left.\mathrm{H}_{2 \mathrm{~b}}\right)$ were tested by hierarchical regressions. Following the guidelines by Aiken and West (1991), the predictor and moderator variables were mean centered before creating an interaction term to minimize multicolinearity effects. The predictors (control and trust) were entered in model 1 and the moderating variable (risk) in model 2, to test for main effects; the interaction terms between risk and each of the two independent variables (control and risk) were entered in model 3. Because the moderation hypotheses establish a specific direction, both were tested using a one-tailed test. 


\section{Results}

\subsection{The impact of benefit realization accountability effectiveness on project performance}

First, we conducted a Confirmatory Factor Analysis to examine the distinctiveness of the multi-item variables in the study. We compared the fit of three models. The first was the hypothesized four-factor model, which included the two accountability approaches (control and trust) in a combined "benefit accountability" factor, as well as risk, efficiency and performance. The second model further combined efficiency and performance to create a nested three-factor model. The third model was a default one-factor model, in which all variables formed one factor. The hypothesized four-factor model $(\mathrm{RMSEA}=0.048 ; \mathrm{CFI}=0.99)$ fits the data better than the three-factor model (RMSEA=0.120; CFI=0.92), and the onefactor model (RMSEA=0.200; CFI=0.73). Furthermore, the Chi-Square difference test showed that the hypothesized four-factor model fits the data significantly better than the three-factor model $\left(\Delta \mathrm{X}^{2}=18.35 ; \Delta \mathrm{df}=3\right)$ for significance level below 0.01. Descriptive statistics and correlations among all four factors (as well as the two benefit accountability management approaches) are presented in Table 1. Results show significant positive correlations between the two management approaches that might be adopted by the project owner in discharging his/her benefit accountability and project efficiency and performance.

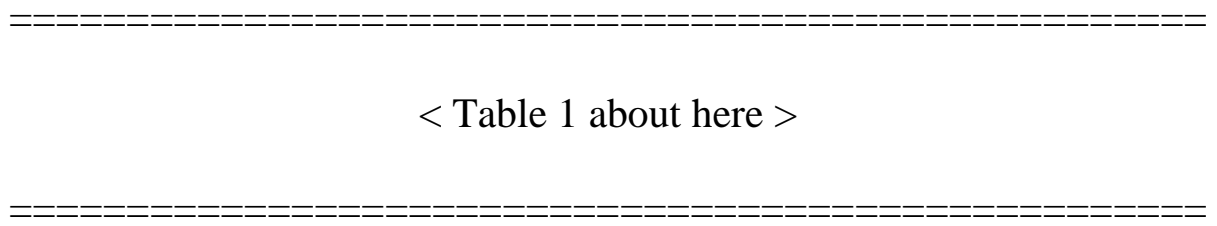

Next, we tested the competing hypotheses $\mathrm{H}_{1 \mathrm{a}}$ and $\mathrm{H}_{1 \mathrm{~b}}$ on the impact of benefit realization accountability effectiveness on project performance, using the four factors identified above: benefit accountability, risk, efficiency and performance. Hypothesis $\mathrm{H}_{1 \mathrm{a}}$ (represented in Figure 2a) tested the direct effect of benefit accountability effectiveness on project performance. While the correlation was significant, the model fit was only marginally 
significant $(\mathrm{RMSEA}=0.11$; $\mathrm{CFI}=0.97)$. The competing hypothesis $\mathrm{H}_{1 \mathrm{~b}}$ proposed that project efficiency mediates the effect of benefit accountability effectiveness on performance. Results of this full mediation model (presented in Figure 2b) are again only marginally significant (RMSEA=0.11; CFI=0.93). As a result, we also analyzed a partial mediation relationship (Figure 2c), which provided better results (RMSEA=0.04; CFI=0.99). Finally, model 4 tested a non-nested alternative partial mediation model (i.e. reversed sequence between efficiency and performance), though with poorer results (RMSEA=0.09; $\mathrm{CFI}=0.96)$. Risk was set as a control variable in all four models.

$<$ Figure 2 about here >

In order to determine the best nested model, a Chi-Square test was conducted to statistically compare the full and partial mediation models. The test showed that the partial mediation model (Figure 2c) fits the data significantly better than the full mediation model $\left(\Delta \mathrm{X}^{2}=14.9 ; \Delta \mathrm{df}=1\right)$ for significance level below 0.001. Additionally, the AIC value showed that this partial mediation model had the smallest value (AIC=60.82), followed by the nonnested partial mediation model (Figure $2 \mathrm{~d}$ ) with $\mathrm{AIC}=67.59$. Hence, we accepted the partial mediation model as the best-fitting model. To confirm the partial mediation effect we calculated the variance accounted for (VAF), which "determines the size of the indirect effect in relation to the total effect" (Hair et al., 2014, p. 225). The VAF value (25\%) falls within the partial mediation range. We conclude that project efficiency partially mediates the relationship between project benefit accountability effectiveness and project performance. Furthermore, because the VAF value is very close to the lower partial mediation effect range (20\%), results suggest that project performance is more appropriate than project efficiency to 
serve as the dependent variable in our moderating analysis of the second research hypothesis below.

\subsection{The moderating effect of risk}

The second set of research hypotheses focused on the moderating effect of risk on the relationship between the two benefit management approaches and project performance. In order to allow a moderation test, the conditions set by Sharma et al. (1981) have been tested first. Results of the correlation analysis (Table 1) suggest no significant correlations between the moderating variable (risk) and both the predictors (control and trust) and the criterion variable (project performance). As a result, this case falls within the second quadrant in Sharma et al.'s model as a full moderator. In other words, the moderating variable is not related neither to the criterion not the predictor, neither it interacts with the predictor. Hence, a moderation analysis was conducted using a stepwise regression, as described earlier. Results, presented in Table 2, confirm that the interactions between risk and control $(\mathrm{p}<0.001)$ and risk and trust $(\mathrm{p}<0.05)$ affect project performance. These analyses support both parts of the second hypothesis.

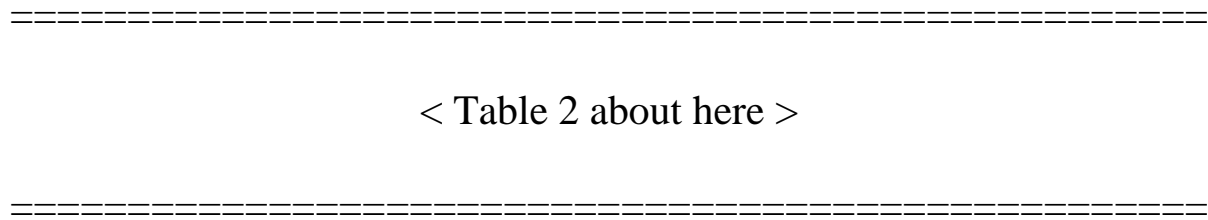

Information from the regression equations was extracted to plot the relationship between trust and control and project performance at low and high levels of risk (Figures 3a and $3 b)$. Low control and low trust pertain to -1 SD below their means. In contrast, high control and high trust refer to +1 SD above their means. 
$<$ Figure 3 about here >

\section{Discussion}

This section provides a discussion of the effectiveness of benefit realization accountability on project performance in various project contexts.

\subsection{The project owner's accountability for benefit realization}

The literature identifies accountability as a core component of effective governance (Abednego \& Ogunlana 2006; Brand 2007). It has become widely accepted that benefit generation is the underlying objective of all projects (Zwikael \& Smyrk 2012). The results of our empirical study have confirmed that assignment of an accountability for benefit realization has a positive effect on project performance. This result is an extension to Shenhar and Dvir's claim (2007) that managers need to take further responsibilities for business results, rather than focus only on project efficiency. Such an accountability is in alignment with: (1) governance literature, which recognizes the importance of ownership (Cai \& Tylecote 2008), (2) principal-agent theory, which requires separation of ownership and control (Eisenhardt 1989), and (3) management literature, which highlights trade-offs between efficiency and effectiveness (Chase et al. 2007).

The incorporation of a project owner into established models of project governance also has fundamental implications for the role of project managers, traditionally the funder's agent. Instead, we suggest a cascading of accountability: from the funder to the project owner for realizing benefits and then from the project owner to the project manager for delivering the outputs that are necessary for achievement of those benefits. The separation of the roles of project manager and project owner can be used as the foundation for a project governance 
model in which the project owner becomes the project manager's principal and the project manager becomes the project owner's agent (Muller \& Turner 2005).

\subsection{The project governance model}

The previous section discussed the role of the project owner in ensuring the realization of project benefits. The role of the project owner is also central for the shape of a project governance model. Whereas previously a project manager interacted directly with the funder, this interaction now takes place with the project owner who in turn liaises with the funder.

The funder commits funds and/or approves the allocation of labor to the project (Zwikael and Smyrk, 2011). However, after approving the business case, the project funder is usually too busy to be actively involved in project execution. Hence, the project funder may choose to appoint a project owner to oversee the development of the project plan (by the project manager), and works closely with the project manager during execution.

The project owner is accountable to the funder for project benefit realization in general and for the fulfillment of the business case in particular. Based on principal-agent theory, the project owner should: (1) not face a conflict of interest, (2) be recognized as a single point of accountability, and (3) be separated from the project manager. Because of the long term time horizon of project benefit realization, it is also important that the project owner has a strategic mindset. The project owner would be expected to chair meetings of the steering committee - a small group of powerful project supporters assembled to support the project owner in the discharge of his/her accountability to the funder by overseeing the project's execution and, later, benefit realization (Zwikael \& Smyrk 2012).

Based on principal-agent theory (Eisenhardt 1989), a project manager is to be held accountable to the project owner for delivering the project's committed outputs, fit-forpurpose, within the constraints of an agreed budget and timeframe and without causing 
undesirable outcomes (Zwikael and Smyrk, 2011). The project manager will usually have a project team to support his/her work in delivering the project's outputs. The generic project governance model based on these principles is presented in Figure 4. Note that because the funder is not actively involved in the project he/she is not an official part of the governance model, but instead has an overseeing role.

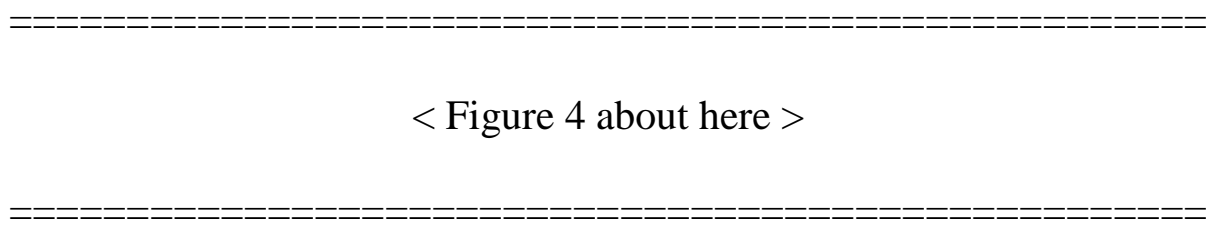

It is to be expected that this model will, from time-to-time, give rise to conflicts between the project owner and manager despite their distinct accountabilities. For example, the project owner may suggest additional improvements in the quality of project outputs to more closely match customer needs - thus enhancing benefit realization. It is to be expected that a project manager may be reluctant to accept such a change because it may have implications on the delivery date of the outputs (for which he/she is accountable). Based on the principal-agent theory, we suggest that if such conflicts emerge, the project owner's view should prevail.

\subsection{The project owner role under various project risk levels}

In addition to confirming the positive relationship between the effective accountability of a project owner for benefit realization and project performance, the results of this study also exposed the moderating effect of risk, thus reinforcing the importance of risk as a contextual construct in project governance. More specifically, we found that under low and high levels of risk each management approach to the discharge of accountability impact project performance differently.

It was found that project owner's control of the of project management process is important in low risk situations (Figure 3a), whereas the project owner's trust in the project 
manager is important in high risk scenarios (Figure 3b). These results are similar to the findings of de Man \& Roijakkers (2009) in their control-trust-risk approach for alliance governance. The following paragraphs suggest how this theory can be operationalized for various project contexts.

High risk projects have more uncertainty regarding output delivery. For example there is no guarantee that a novel product sought from an $R \& D$ project will be delivered. As a result, project managers become preoccupied with the relatively short term problems of project execution and less concerned with the longer term goal of realizing benefits. In such cases, additional control by the project owner of the project management process is likely to focus on mitigating short term threats. These actions may not be readily accepted by the project manager (who could see them as a form of interference). Consequently, such actions may have little, if any, positive impact on long term project performance. On the other hand, in low risk projects, (such as a road construction project) delivery of outputs is more certain. In these cases attempts by the project owner to intervene in the project management processes may be seen as complementary to existing output delivery control activities, thus having a positive impact on eventual long term benefit realization. For example, involvement of this kind by a project owner could well be directed at judging the acceptability of gaps between planned and actual levels of performance (as reflected in the project plan) and then facilitating actions that will close any unacceptable gaps. A practical and useful control approach is conducting project audits or stage-gate reviews (Turner, 2009).

Trust of the project owner in the project manager will have the greatest impact on the performance of high risk projects because of two potential mechanisms. High levels of trust are likely to encourage the assembly of a high quality business case and project plan at the beginning of a project and strong leadership during benefit realization at its end-both contributing to project performance (Zwikael \& Smyrk 2011). 


\section{Conclusions}

While in the past, the literature has focused on efficient project output delivery (for example, ensuring a bridge construction is completed on time), more recently it has acknowledged the importance of benefit realization (for example, ensuring the number of accidents on this road is reduced). Despite this shift in emphasis (e.g. Zwikael and Smyrk, 2012), the literature has lagged behind in accommodating the implications of these developments for project governance. As a result, project governance models are still concerned primarily with a sole accountability for output delivery. Following previous attempts to incorporate benefit accountabilities into project governance models (e.g. OGC 2009; Muller \& Turner 2005), and based on principal-agent theory (Eisenhardt 1989), this paper supports an appointment of a project owner for each project (Zwikael and Smyrk, 2012) and suggests criteria for such an appointment. Furthermore, we propose a generic project governance model, which includes two key players: the project owner (who represents the project funder's interests in the project) and the project manager. Commonly, a steering committee (lead by the project owner) and a project team (lead by the project manager) will also be involved.

The title of our paper paraphrases that of a paper on control-trust risk theory by de Man and Roijakkers (2009), reflecting our objective of extending this theory to the project governance environment. Accordingly, our paper also discusses the effectiveness of the managerial approaches of control and trust (Todeva and Knoke 2005) in defining the role of the project owner. We propose that a management approach for the project owner based on trust in the project manager will be more effective in high risk projects, whereas one based on control of the project management process will be more effective in low risk situations. 
Recapturing our research questions we conclude that the assignment of benefit realization accountability improves project performance. A project owner should be assigned the accountability for realizing the business case in general and securing the flow of target benefits in particular. The project owner is, effectively, the funder's agent. Ideally, the project owner will chair the steering committee. Accordingly, a project manager is to be held accountable by the owner for delivery of project outputs.

It is important to note here various limitations of this research, including the use of an underdeveloped scale to gauge accountability for benefit realization, data collection at a single point in time, and the application of principal-agent theory which has been the subject of some criticisms in the literature (for example, see Munari et al. 2010). Another limitation is that this paper relies on the literature which suggests that trust and control are alternative managerial approaches, whereas it is important to state that others perceive them as related, in particular when trust levels are high, project owners may give more control to project managers. Finally, whereas this study tested moderation and mediation effects separately, future research might examine a combined approach for moderation-mediation analysis, as well as validate the proposed theoretical framework in various types of project, organizational contexts, and cultures. 


\section{References}

Abednego, M. P. and S. O. Ogunlana., 2006. Good project governance for proper risk allocation in public-private partnerships in Indonesia. International Journal of Project Management, 24 (7), 622-634.

Aghion, P. and J. Tirole., 1997. Formal and real authority in organizations. The Journal of Political Economy, 105 (1), 1-29.

Aiken, L. and S. West. 1991. Multiple Regression: Testing and Interpreting Interactions, Newbury Park, CA: Sage.

Akaike, H., 1987. Factor analysis and AIC. Psychometrica, 52, 317-332.

Aoki, M. 2001. Towards a comparative institutional analysis. Cambridge: MIT Press. Arena, P. 2009. Patrick S. Renz, Review of Project Governance: Implementing Corporate Governance and Business Ethics in Nonprofit Organizations. J Manag Gov, 13:355-363.

Aviram-Unger, E., Zwikael, O. and Restubog, S., 2013. Revisiting goals, feedback, recognition and performance success: the case of project teams. Group \& Organization Management: An International Journal, 38 (5), 570-600

Bekker, M. C. 2014. Project governance: "schools of thought". South African Journal of Economic and Management Sciences, 17, 22-32

Bakker, R. M., Boros, S., Kenis, P. and Oerlemans, L. A. G., 2013. It's only temporary: Time Frame and the Dynamics of creative project teams. British Journal of Management, 24, 383-397.

Bentler, P. M. and D. G. Bonett., 1980. "Significance tests and goodness of fit in the analysis of covariance structures." Psychological Bulletin, 88: 588-606. 
Bozec, R., M. Dia. and Y. Bozec., 2010. Governance-performance relationship: A reexamination using technical efficiency measures. British Journal of Management, $21(3), 684-700$.

Brand, H., 2007. Good governance for the public's health. European Journal of Public Health, 17 (6), 541.

Browne, M. W. and R. Cudeck. 1993. Alternative ways of assessing model fit. In: Bollen, K.A., Long, J.S. (Eds.). Testing Structural Equations Models. Sage, Newbury Park.

Bryde, D. J., 2005. Methods for Managing Different Perspectives of Project Success. British Journal of Management, 16 (2), 119-131.

Cai, J. and A. Tylecote. 2008. Corporate governance and technological dynamism of Chinese firms in mobile telecommunications: A quantitative study. Research Policy, 37 (10), 1790-1811.

Chapman, C. and S. Ward. 2004. Why risk efficiency is a key aspect of best practice projects. International Journal of Project Management, 22 (8), 619-631.

Chase, R. B., F. R. Jacobs and N. J. Aquilano. 2007. Operations Management for Competitive Advantage with Global Cases. $11^{\text {th }}$ Edition. McGraw-Hill.

Cooke-Davies, T. 2002. “The 'real' success factors on projects.” International Journal of Project Management, 20: 185-190.

Cui, Z., C. Loch., B. Grossmann and R. He. 2012. How provider selection and management contribute to successful innovation outsourcing: An empirical study at Siemens. Production and Operations Management, 21 (1), 29-48.

Das, T. K., Teng, B. S. 2001. Trust, control, and risk in strategic alliances: an integrated framework. Organization Studies, 22, 251-283. 
Davis, J. H., Schoorman, F. D., Donaldson, L. 1997. Toward a stewardship theory of management. Academy of Management Review, 22(1), 20-47.

de Man, A. and N. Roijakkers. 2009. Alliance governance: Balancing control and trust in dealing with risk. Long Range Planning, 42, 75-95.

Du Plessis, J. J., J. McConvill. and M. Bagaric. 2005. Principles of Contemporary Corporate Governance. Cambridge University Press: Melbourne, Australia.

Dvir, D. and T. Lechler. 2004. Plans are nothing, changing plans is everything: the impact of changes on project success. Research Policy, 33, 1-15.

Eisenhardt, K. M. 1989. Agency theory: An assessment and review. The Academy of Management Review, 14 (1), 57-74.

Fama, E. F. and M. C. Jensen. 1983. Separation of ownership and control. Journal of Law and Economics, XXVI, June.

Forbes, D. P. and F. J. Milliken. 1999. Cognition and corporate governance: understanding boards of directors as strategic decision-making groups. Academy of Management Review, 24, 489-505.

Freeman, R. E. 1984. Strategic management: A stakeholder approach. Marshfield: Pitman.

Garland, R. 2009. Project Governance: A Practical Guide to Efficient Project DecisionMaking. Kogan Page.

Hair, J. F., Hult, G. T. M., Ringle, C., Sarstedt, M. 2014. A primer on partial least squares structural equations modeling (PLS-SEM). Thousand Oaks, Calif., SAGE Publications.

Herroelen, W. 2005. Project scheduling-theory and practice. Production and Operations Management, 14 (4), 413-432. 
Huse, M. 2005. Accountability and creating accountability: A framework for exploring behavioural perspectives of corporate governance. British Journal of Management, 16 , S65-S79.

Jensen, M. C. 2000. A theory of the firm: governance, residual claims, and organizational forms. Cambridge, USA: Harvard University Press.

Johnson, R. B., and Onwuegbuzie, A. J. 2004. Mixed methods research: A research paradigm whose time has come. Educational Researcher, 33(7), 14-26.

Jugdev. K. and R. Muller. 2005. A retrospective look at our evolving understanding of project success. Project Management Journal, 36 (4), 19-31.

Kerzner, H. 2009. Project Management: A Systems Approach to Planning, Scheduling and Controlling. 10th edition, John Wiley and Sons.

Lechler, T. and M. Cohen. 2009. Exploring the role of steering committees in realizing value from project management. Project Management Journal, 40 (1), 42-54.

Lechler, T. and D. Dvir. 2010. An alternative taxonomy of project management structures: linking project management structures and project success. IEEE Transactions on Engineering Management, 57 (2), 198-210.

Lee, J. Y., M. Swink and T. Pandejpong. 2011. The roles of worker expertise, information sharing quality, and psychological safety in manufacturing process innovation: An intellectual capital perspective. Production and Operations Management, 20 (4), 556-570.

Lewis, M. W., M. A. Welsh., G. E. Dehler and S. G. Green. 2002. Product development tensions: Exploring contrasting styles of project management. The Academy of Management Journal, 45 (3), 546-564. 
Malach-Pines, A., D. Dvir and A. Sadeh. 2009. Project manager-project (PM-P) fit and project success. International Journal of Operations and Production Management, 29 (3), 268-291.

Marle, F., L. A. Vidal and J. C. Bocquet. 2013. Interactions-based risk clustering methodologies and algorithms for complex project management. International Journal of Production Economics, 142, 225-234.

Mayer, R., J. H. Davis and F. D. Schoorman. 1995. An integrative model of organizational trust. Academy of Management Review, 20 (3), 709-734.

Mihm, J., C. H. Loch., D. Wilkinson and B. A. Huberman. 2010. Hierarchical structure and search in complex organizations. Management Science, 56 (5), 831-848.

Morris, P.W.G., \& Geraldi, J., 2011. Managing the institutional context for projects. Project Management Journal, 42(6): 20-32.

Müller, R., J. Geraldi and J. R. Turner. 2012. Relationships between leadership and success in different types of project complexities. IEEE Transactions on Engineering Management, 59 (1), 77-90.

Muller, R. and J. R. Turner. 2005. The impact of principal-agent relationship and contract type on communication between project owner and manager. International Journal of Project Management, 23 (5), 398-403.

Müller, R. 2009. Project Governance. Gower Publishing Limited: Farnham, England.

Munari, F., R. Oriani and M. Sobrero. 2010. The effects of owner identity and external governance systems on R\&D investments: A study of western European firms. Research Policy, 39 (8), 1093-1104.

Narayanan, S., S. Balasubramanian and J. M. Swaminathan. 2011. Managing outsourced software projects: An analysis of project performance and customer satisfaction. Production and Operations Management, 20 (4), 508-521. 
Nigro, G. L., G. Perrone and S. Chiapparrone. 2012. Governance forms drivers in biopharmaceutical inter-firm relationships. International Journal of Production Economics, 140 (2), 604-613.

OECD. Organization for Economic Co-operation and Development. 2004. OECD Principles of Corporate Governance. Paris: OECD.

OGC - UK Office of Government Commerce. 2009. Managing Successful Programmes. The Stationery Office, Norwich, UK.

Pfeffer, J. and G. R. Salancik. 1978. The External Control of Organizations: A Resource Dependence Perspective, Stanford, CA: Stanford. University Press.

Pinto, J. K. and J. E. Prescott. 1990. Planning and tactical factors in the project implementation process. Journal of Management Studies, 27 (3), 305-327.

PMI (2013). A guide to the project management body of knowledge (PMBOK® Guide) (5th Ed.). Newton Square, PA: Project Management Institute.

Pryke, S. D. 2005. Towards a social network theory of project governance. Construction Management and Economics, 23 (9), 927-939.

Remenyi, D., T. White and M. Sherwood-Smith. 1997. Information systems management: The need for a post-modern approach. International Journal of Information Management, 17 (6), 421-435.

Renz, P. S. 2007. Project Governance: Implementing Corporate Governance and Business Ethics in Nonprofit Organizations. Physica-Verlag, Heidelberg, Germany. Roberts, J., NcNulty, T. and Stiles, P. 2005. Beyond agency conceptions of the work of the non-executive director: Creating accountability in the boardroom. British Journal of Management, 16, S5-S26. 
Ruuska, I., Ahola, T., Artto, K. Locatelli, G. \& Mancini, M. 2011. A new governance approach for multi-firm projects: lessons from Olkiluoto 3 and Flamanville 3 nuclear power plant projects. International Journal of Project Management, 29(6): 647-660.

Scott-Young, C. and D. Samson. 2009. Team management for fast projects: An empirical study of process industries. International Journal of Operations and Production Management, 29 (6), 612-635.

Scott-Young, C. and D. Samson. 2008. Project success and project team management: Evidence from capital projects in the process industries. Journal of Operations Management, 26 (6), 749-766.

Sharma, S., Durand, R., \& Gur-Arie, O. 1981. Identification and Analysis of Moderator Variables. Journal of Marketing Research, 18(August), 291-300.

Shenhar, A. J. 2001. One size does not fit all projects: Exploring classical contingency domains. Management Science, 47 (3), 394-414.

Shenhar, A. J. and D. Dvir. 2007. Reinventing Project Management: The Diamond Approach to Successful Growth and Innovation. Harvard Business School Press.

Simon, H. A. 1976. Administrative Behavior (3rd ed.). New York: The Free Press.

Sommer, S. C. and C. H. Loch. 2009. Incentive contracts in projects with unforeseeable uncertainty. Production and Operations Management, 18 (2), 185-196.

Stoker, G. 1998. Governance as theory: Five propositions. International Social Science Journal, 50 (155), 17-28.

Sundstrom, E., K. P. De Meuse and D. Futrell. 1990. Work teams: Applications and effectiveness. American Psychologist, 45 (2), 120-133.

Todeva, E. and Knoke, D. 2005. Strategic alliances and models of collaboration. Management Decision, 43 (1), 123-148. 
Too, E. G. and Weaver, P. 2013. The management of project management: A conceptual framework for project governance. International Journal of Project Management.

Turner, J. R. 2009. Governance of project-based management. In Handbook of Projectbased Management. McGraw Hill

Wang, J. and C. Yang. 2012. Flexibility planning for managing R\&D projects under risk. International Journal of Production Economics, 135 (2), 823-831.

Ward, J. and E. Daniel. 2006. Benefits Management: Delivering Value from IS \& IT Investments. John Wiley \& Sons Inc: New York.

Winch, G. 2001. Governing the project process: A conceptual framework. Construction Management and Economics, 19(8), 799-808.

Zwikael, O. and A. Sadeh. 2007. Planning effort as an effective risk management tool. Journal of Operations Management, 25 (4), 755-767.

Zwikael, O. and J. R. Smyrk. 2011. Project Management for the Creation of Organisational Value. Springer-Verlag, London, UK.

Zwikael, O. and J. Smyrk. 2012. A general framework for gauging the performance of initiatives to enhance organizational value. British Journal of Management, 23, S6S22.

Zwikael, O. and M. Ahn. 2011. The effectiveness of risk management: an analysis of project risk planning across countries and industries. Risk Analysis: An International Journal, 31 (1), 25-37.

Zwikael, O. and S. Globerson. 2006. From critical success factors to critical success processes. International Journal of Production Research, 44(17), 3433 - 3449. 


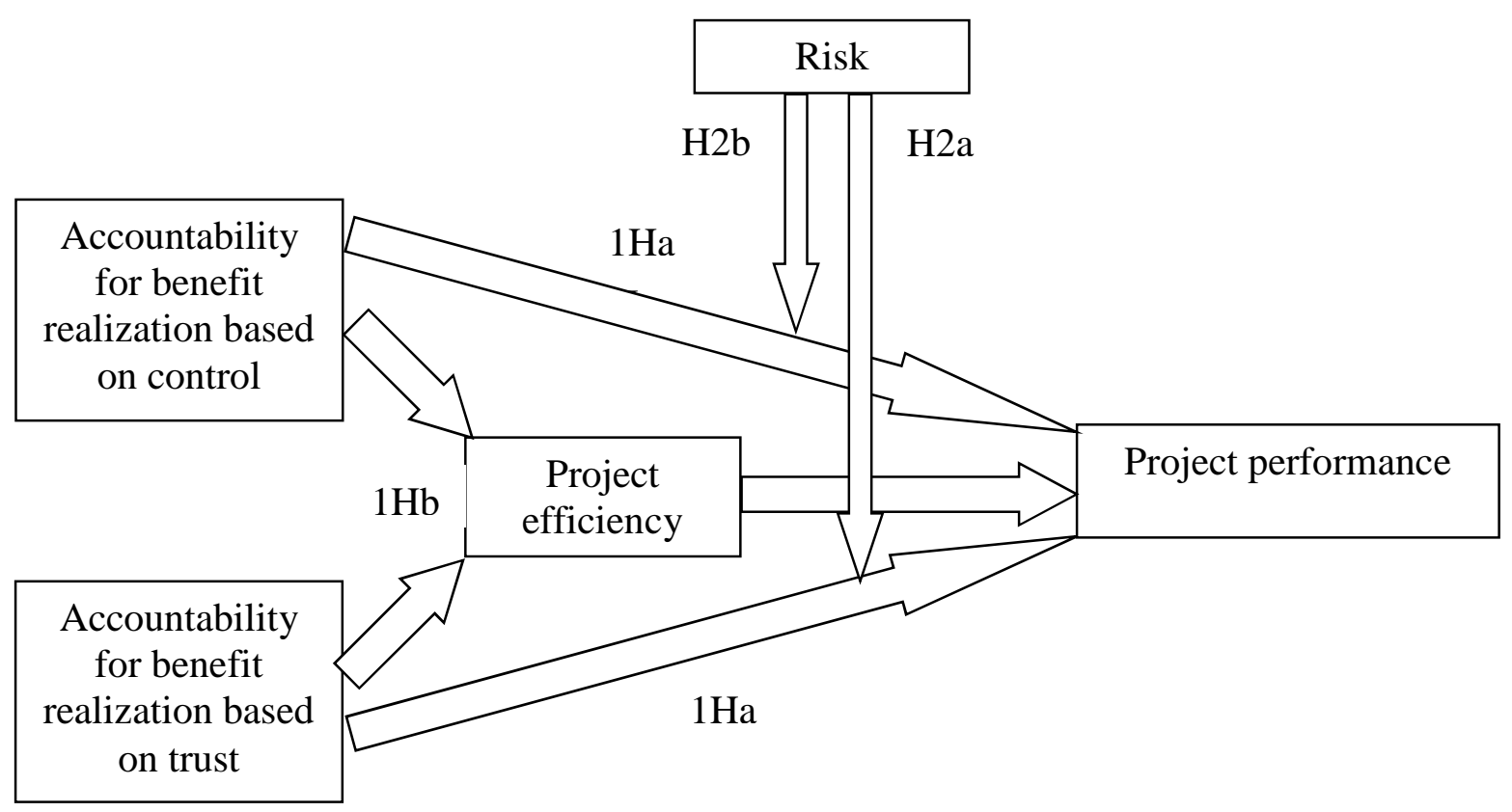

Figure 1. The study theoretical model (including competing hypotheses) 


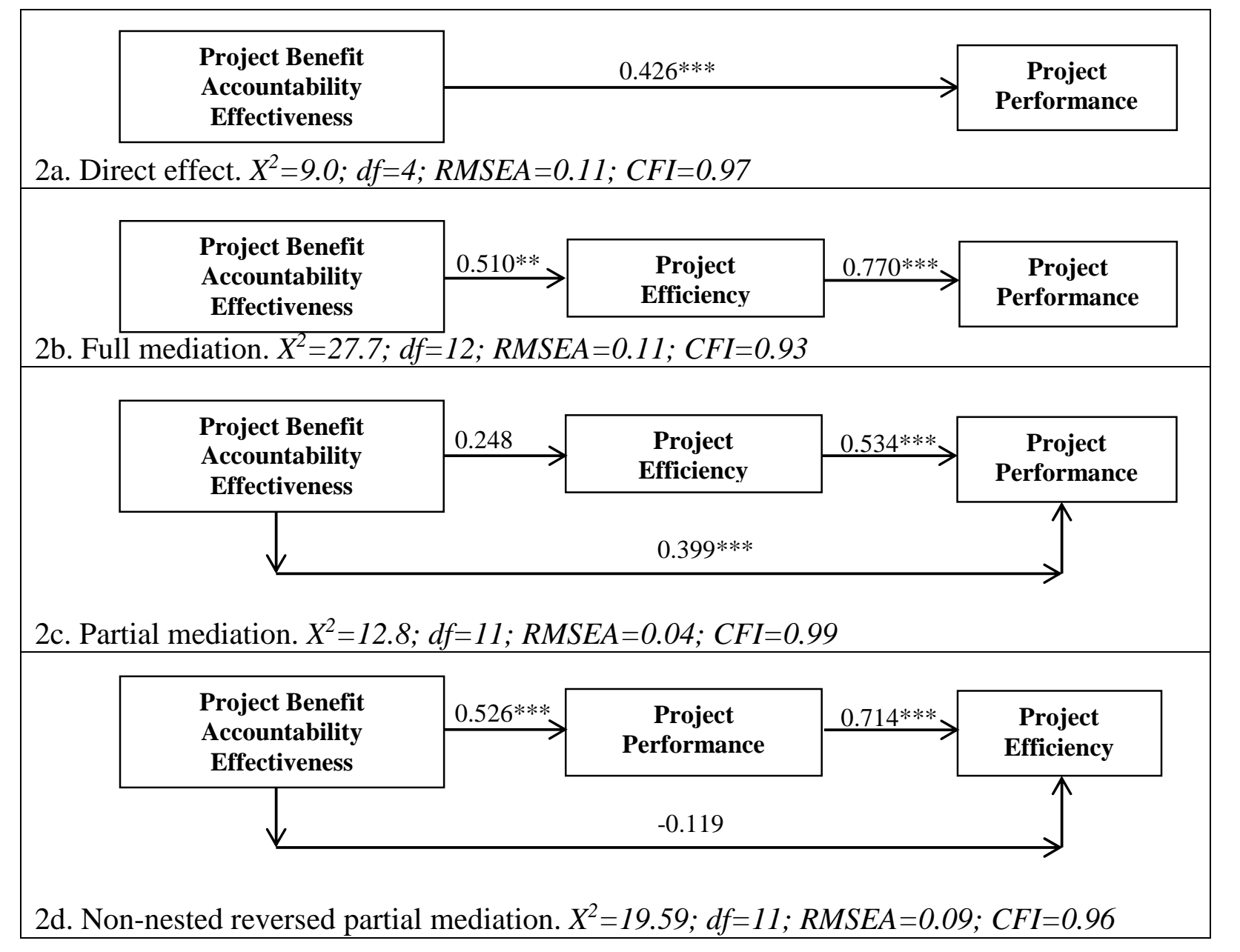

Figure 2. Competing structural equation models for the impact of benefit accountability effectiveness on project performance (controlled by level of risk)

Note: RMSEA = Root Mean Square Error of Approximation; CFI = Comparative Fit Index 


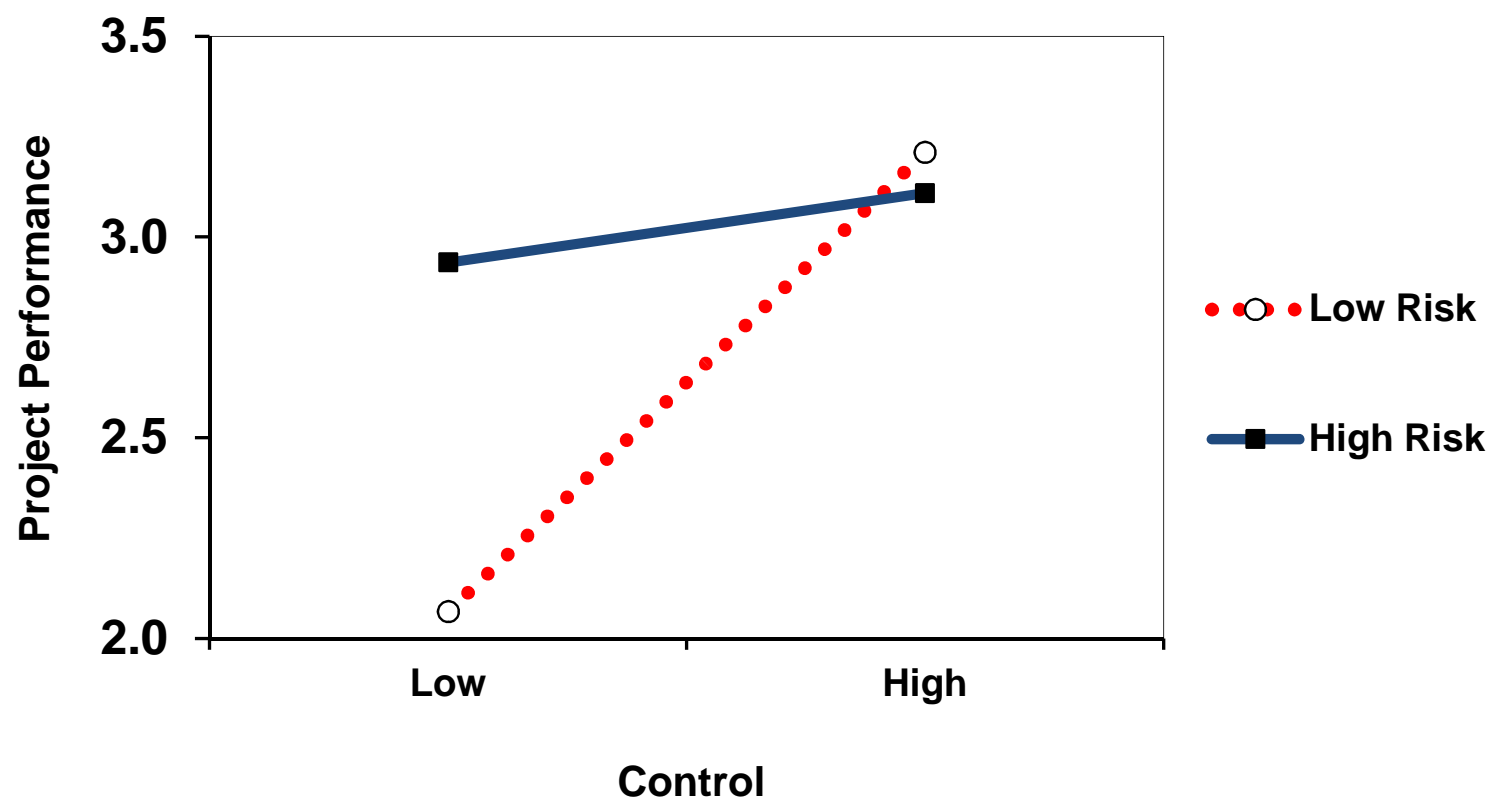

Figure 3a. The moderating effect of risk on the relationship between control and project performance

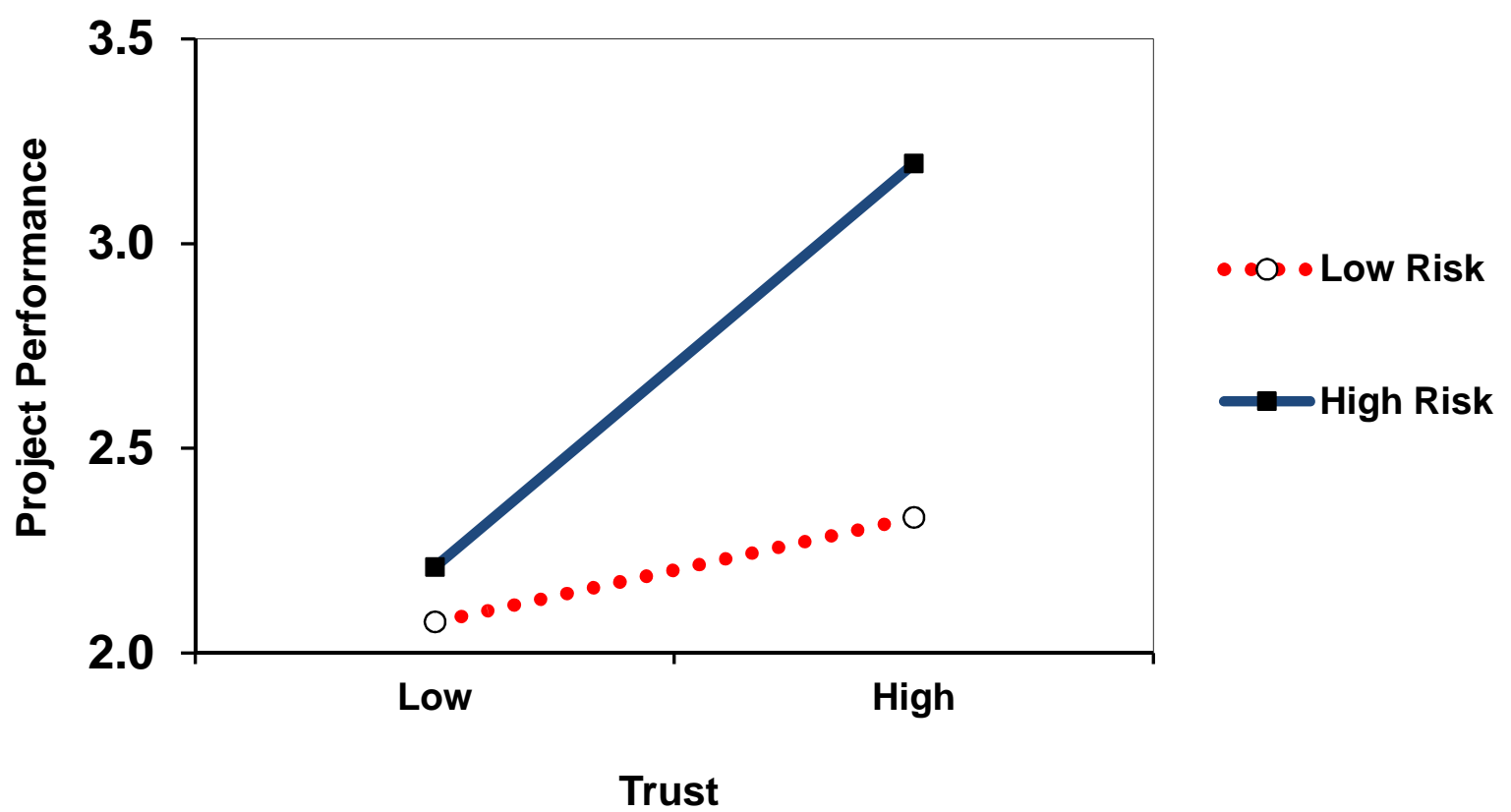

Figure $3 \mathrm{~b}$. The moderating effect of risk on the relationship between trust and project performance 


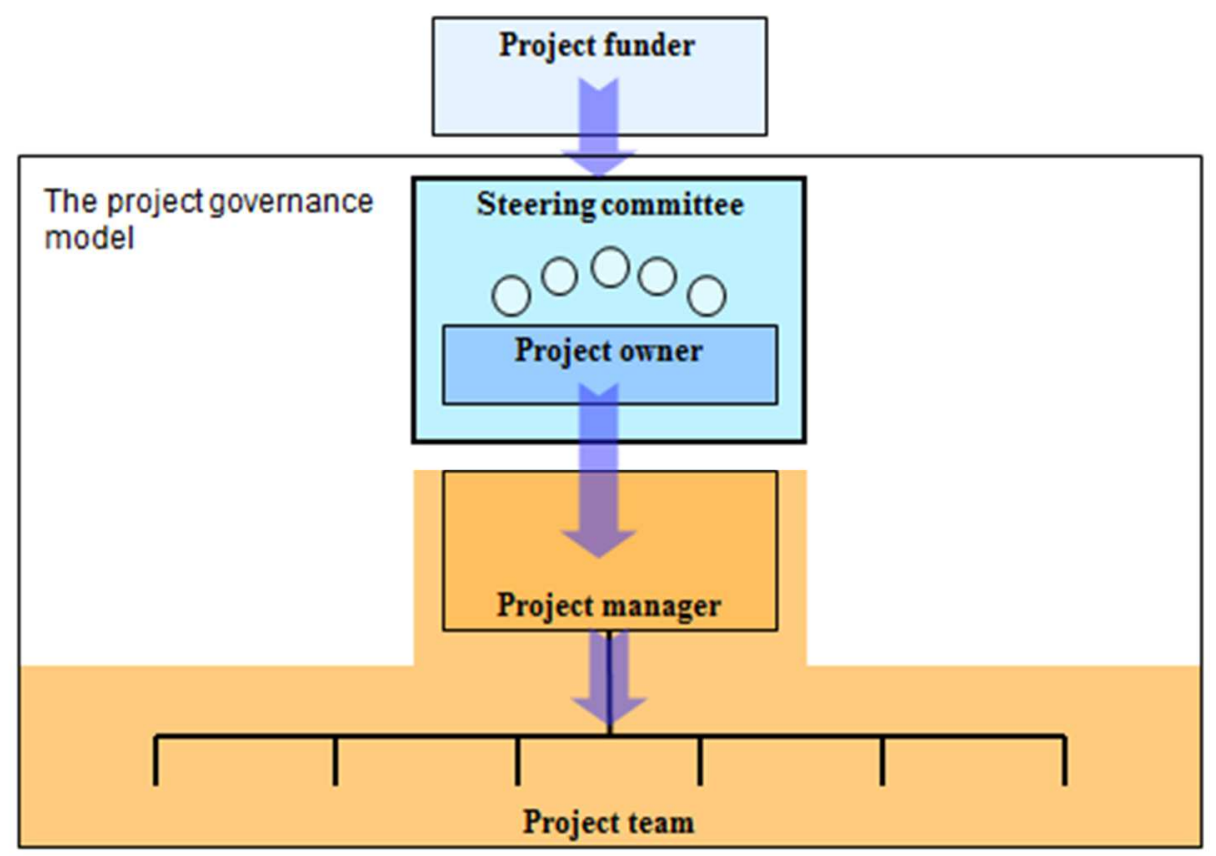

Figure 4. The project governance model 


\begin{tabular}{|l|l|l|l|l|l|l|l|}
\hline & Mean & STD & \multicolumn{1}{|c|}{ (1) } & \multicolumn{1}{|c|}{ (1a) } & \multicolumn{1}{|c|}{ (1b) } & (2) & (3) \\
\hline $\begin{array}{l}\text { (1) Project benefit } \\
\text { accountability effectiveness }\end{array}$ & 3.40 & 1.07 & $(0.78)$ & & & & \\
\hline (1a) Control (1-5) & 3.34 & 1.21 & & NA & & & \\
\hline (1b) Trust (1-5) & 3.46 & 1.16 & & $0.634 * * *$ & NA & & \\
\hline (2) Project efficiency (\%) & 27.30 & 34.46 & $0.213^{*}$ & $0.202^{*}$ & 0.183 & $(0.69)$ & \\
\hline (3) Project performance (1-5) & 3.74 & 0.95 & $0.445^{* * * *}$ & $0.374 * * *$ & $0.431^{* * *}$ & $0.510^{* * * *}$ & $(0.84)$ \\
\hline (4) Risk (1-5) & 3.61 & 0.89 & -0.039 & 0.053 & -0.128 & 0.029 & 0.184 \\
\hline
\end{tabular}

Table 1. Pearson correlations among the study's continuous variables $\left({ }^{*} p<0.05 ; * * p<0.01 ; * * * p<0.001\right)$ 


\begin{tabular}{|l|l|l|l|}
\hline & \multicolumn{1}{|c|}{ Model 1 } & \multicolumn{1}{c|}{ Model 2 } & \multicolumn{1}{c|}{ Model 3 } \\
\hline Control & 0.169 & 0.118 & 0.157 \\
\hline Trust & $0.324 * *$ & $0.386^{* * *}$ & $0.325^{* *}$ \\
\hline Risk & & $0.227 * *$ & $0.239 * *$ \\
\hline Control * Risk & & & $-0.368^{* * *}$ \\
\hline Trust * Risk & & & $0.171^{*}$ \\
\hline F change & $12.603 * * *$ & $6.462 * *$ & $6.097 * *$ \\
\hline F value & $12.603 * * *$ & $11.020^{* * *}$ & $9.738^{* * *}$ \\
\hline R squared & 0.203 & 0.252 & 0.337 \\
\hline
\end{tabular}

Table 2. The moderating effect of risk on the effectiveness of management approaches on project performance (one-tailed test)

$(* p<0.05 ; * * p<0.01 ; * * * p<0.001)$ 